\title{
Application of various antioxidants in the treatment of influenza
}

\section{A. Dolganova ${ }^{1}$ and B.P. Sharonov ${ }^{2}$}

\author{
${ }^{1}$ Universidade Luterana do Brasil, Canoas, RS, Brasil \\ ${ }^{2}$ Pure Biopreparations Research Institute, St. Petersburg, Russia
}

\author{
Correspondence \\ A. Dolganova \\ Hospital da Universidade Luterana \\ do Brasil \\ Rua Alvaro Alvim, 400 \\ 90420-020 Porto Alegre, RS \\ Brasil \\ Fax: 55 (051) 331-9944
}

Received September 4, 1996 Accepted August 27, 1997

\begin{abstract}
We determined the effect of the antioxidants superoxide dismutase, desferrioxamine and allopurinol on the survival of male CBA mice infected intranasally with $2-5 \mathrm{LD}_{50}$ lung influenza virus A/Aichi/2/68. Survival for at least 20 days was observed for $45 \%$ of the mice that received $1000 \mathrm{U} /$ day superoxide dismutase prepared from red blood cells on days 5, 6, 7 and 8 after infection, and $75 \%$ survival was observed for mice that received the same dose on days 4, 5, 6, 7 and 8 . Desferrioxamine, $25 \mathrm{mg} / \mathrm{kg}$ per day and $100 \mathrm{mg} / \mathrm{kg}$ per day injected subcutaneously, resulted in survival rates of 5 and $0 \%$, respectively, compared to $10 \%$ survival observed for saline-injected controls. Allopurinol at doses of 5 to $50 \mathrm{mg} / \mathrm{kg}$ per day had no effect on mouse survival. These data demonstrate the efficacy of superoxide dismutase for the protection of mice against hemorrhagic lung edema. The ineffectiveness of allopurinol suggests that the xanthine oxidase system does not play a major role in hemorrhage or lung edema and that caution is necessary when desferrioxamine is administered during an acute inflammatory process accompanied by erythrocyte lysis.
\end{abstract}

Key words

- Free radicals

- Influenza

- Antioxidant

- Desferrioxamine

- Superoxide dismutase

- Allopurinol

....................
The question of how to effectively treat influenza infection after the onset of virus resistance to typical chemotherapeutic drugs is still unsolved (1). The effectiveness of most anti-influenza drugs correlates with the suppression of virus reproduction and this is why these medications are effective only during the early phase of infection when intensive reproduction of the virus takes place in the upper respiratory tract epithelium and are ineffective later during infection when virus multiplication no longer plays a major role in the development of the infection. The role of free radical processes in the pathogenesis of influenza-induced hemorrhagic lung edema has been reported and the poten- tial treatment with antioxidant drugs has been discussed recently $(2,3)$.

The objective of the present study was to compare the action of some antioxidants on mouse survival during influenza infection.

It has been proposed that superoxide radical $\left(\mathrm{O}_{2}{ }^{\bullet-}\right)$ generation plays an important role in the pathogenesis of influenza infection and it is assumed that the xanthine-xanthine oxidase system is responsible for $\mathrm{O}_{2}{ }^{\bullet-}$ generation and for the activation of free radical processes during influenza (4). Since allopurinol is a powerful inhibitor of xanthine oxidase (5) we used this drug in our experiments.

We also studied superoxide dismutase 
(SOD), an enzyme that catalyzes the inactivation of the superoxide radical by a dismutation reaction (5):

$$
\mathrm{O}_{2}{ }^{--}+\mathrm{O}_{2}{ }^{\bullet-}+2 \mathrm{H}^{+} \longrightarrow \mathrm{H}_{2} \mathrm{O}_{2}+\mathrm{O}_{2}
$$

Thus, SOD was used in our experiments to trap $\mathrm{O}_{2}{ }^{\bullet-}$ which is generally considered to be the major factor in oxygen toxicity (5).

The morphological substrate of influenza infection is hemorrhagic lung edema and influenza virus can induce erythrocyte hemolysis with the release of hemoglobin (6). The iron released from hemoglobin can catalyze the Haber-Weiss reaction forming hydroxyl radicals (7):

$$
\mathrm{H}_{2} \mathrm{O}_{2}+\mathrm{O}_{2} \cdot-\underset{\mathrm{Fe}}{\longrightarrow} \mathrm{O}_{2}+\mathrm{OH} \bullet+\mathrm{OH}^{-}
$$

The reactivity of hydroxyl radicals is so great that, when formed in a living system, they will react immediately with whatever biological molecule is in their vicinity, thus producing secondary radical(s). Since the iron chelator desferrioxamine (DEF) is a powerful inhibitor of hydroxyl radical formation dependent on the presence of iron

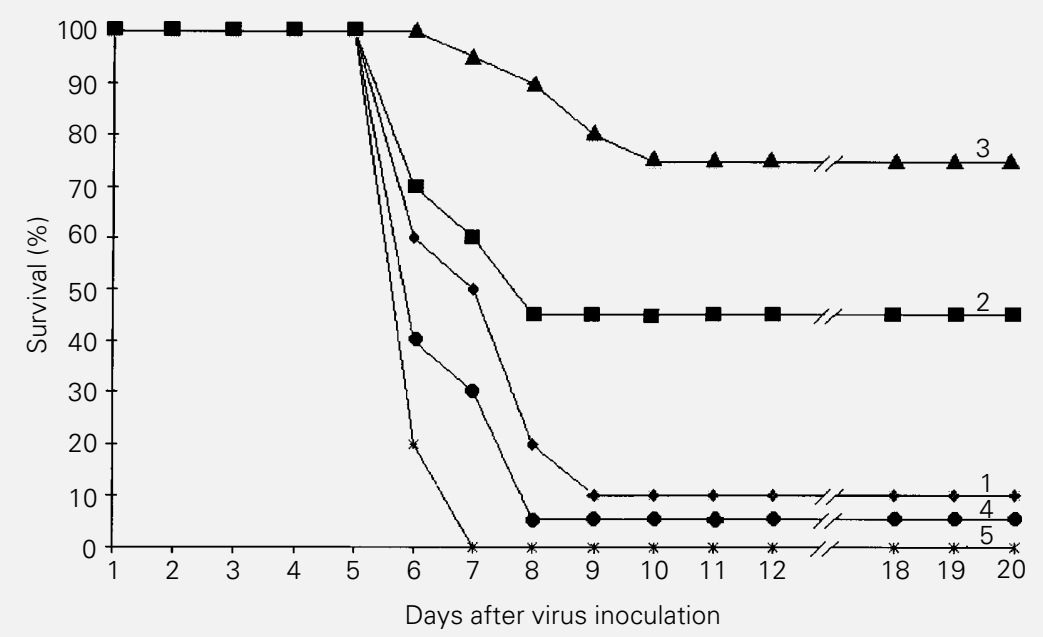

Figure 1 - Effect of antioxidant treatment on the mortality of mice infected with influenza virus. Male CBA mice were infected intranasally with $2-5$ LD50 lung influenza virus A/Aichi/ 2/68 (H2N2). Data are reported as the mean of 3 independent experiments for which 20 mice were used for each group. Curve 1: Control group. Curve 2: SOD, $1000 \mathrm{U} /$ day iv on days 5, 6, 7 and 8 after inoculation. Curve 3: SOD, $1000 \mathrm{U} /$ day iv on days 4, 5, 6, 7 and 8 after inoculation. Curve 4: Desferrioxamine, $25 \mathrm{mg} / \mathrm{kg}$ per day $s c$, divided into two applications. Curve 5: Desferrioxamine, $100 \mathrm{mg} / \mathrm{kg}$ per day $s c$, divided into two applications. salts (8), DEF was used as the third drug in our experiments.

Male mice of the CBA line were infected intranasally with lung influenza virus $\mathrm{A} /$ Aichi/2/68 (H2N2) adapted to mice at the dose of 2-5 LD 50 . Desferrioxamine B (Desferal) was obtained from Ciba-Geigy (Basel, Switzerland) and administered subcutaneously at a daily dose of 5 to $150 \mathrm{mg} / \mathrm{kg}$, twice a day. Human erythrocyte superoxide dismutase was obtained from AO Rosbio (St. Petersburg, Russia) and administered $i v$ at the dose of $1000 \mathrm{U}$ once a day. Allopurinol was purchased from Sigma (St. Louis, MO) and administered orally at doses of 5 to 50 $\mathrm{mg} / \mathrm{kg}$ once a day.

All drugs were administered during the late period of infection on the 4th or 5th day after virus inoculation. The control group of infected mice received saline iv or heatinactivated SOD.

Mouse survival curves for different treatments are shown in Figure 1. Mice that received saline or heat-inactivated SOD (curve 1) had similar $10 \%$ survival rates. SOD was effective (45\% survival) in protecting the mice when given on days 5, 6, 7 and 8 (curve 2 ) and even more effective (75\% survival) when treatment was started earlier, i.e., given on days 4, 5, 6, 7 and 8 (curve 3). Administration of DEF (curves 4 and 5) increased mortality when compared to saline-treated controls. These data demonstrate the protective effect of SOD against influenza virus mortality in CBA mice.

Allopurinol at doses of 5 to $50 \mathrm{mg} / \mathrm{kg}$ per day did not show any effect on mouse survival rate, which did not differ from control mice (data not shown). This lack of effect of allopurinol confirms the suggestion that the main source of free radicals during influenza-caused lung edema seems to be due to activated neutrophils (9) which appear in large numbers in the bronchoalveolar fluid and lungs of infected mice and not to the xanthine-xanthine oxidase system as proposed by others (4). It has been shown that 
SOD can prevent $\mathrm{O}_{2}^{\bullet-}$-dependent formation of a neutrophil chemotactic factor (10).

We suggest that in the present experiments SOD was effective mainly due to its ability to inhibit neutrophil influx into the lungs by decreasing the concentration of the chemotactic factor and therefore by rupture of the "feedback loop" during the inflammation process.

The results obtained with DEF were unexpected. Doses of 10, 25 and $50 \mathrm{mg} / \mathrm{kg}$ per day potentiated the effect of the virus and increased mortality (Figure 1, curve 4) and more than $100 \mathrm{mg} / \mathrm{kg}$ led to the rapid death of all the mice, i.e., 5-7 days after inoculation (Figure 1, curve 5). DEF at the dose of 5 $\mathrm{mg} / \mathrm{kg}$ per day had no effect on the survival of infected mice. Since the $\mathrm{LD}_{50}$ for mice is $250 \mathrm{mg} / \mathrm{kg}$ per day (11), the death of mice inoculated with doses of 25 to $100 \mathrm{mg} / \mathrm{kg}$ per day was not due to the toxicity of DEF. Indeed, doses of 50, 100 and $150 \mathrm{mg} / \mathrm{kg}$ per day had no effect on healthy mice. It has been shown that DEF can stimulate the acute inflammatory induction phase of chronic allergic monoarthritis at low doses (12), presumably due to its prooxidant effect under certain conditions. Indeed in our experiments both low (10 mg/kg per day) and high (150 $\mathrm{mg} / \mathrm{kg}$ per day) doses of DEF aggravated the condition of mice infected with influenza virus. The prooxidant properties of DEF have been reported by others (13-16). In vitro studies have shown that in the presence of $\mathrm{O}_{2}$ and Fe(II), DEF is a prooxidant (17). In our experimental model the pathological process occurs in the lungs which have a high level of oxygen compared to other tissues. When this process is accompanied by erythrocyte lysis and hemoglobin release with an increase in $\mathrm{Fe}$ (II) concentration, conditions similar to those reported by Yegorov (17) probably occur, and therefore DEF acts as a prooxidant leading to aggravation of the pathological process and, in the case of infection with the influenza virus, to increased mortality.

The present results suggest that SOD can protect against the hemorrhagic lung edema caused by influenza virus and furthermore indicate that caution is necessary when DEF is administered during the acute inflammatory process accompanied by erythrocyte lysis. The lack of effect of allopurinol indicates that the xanthine-xanthine oxidase system does not play a major role in the hemorrhagic lung edema of mice infected with influenza virus.

\section{References}

1. Hay AJ, Grambas S \& Bennet MS (1991). Resistance of influenza $A$ viruses to amantadine and rimantadine. In: Kumar A (Editor), Advances in Molecular Biology and Targeted Treatment for ARDS. Plenum, New York, 341-353.

2. Sharonov BP, Dolganova AV \& Kiselev OI (1991). Synergism of processes of generating active forms of oxygen and proteolysis as a possible reason for developing influenza. Doklady Akademii Nauk SSSR, 317: 1265-1267

3. Buffinton GD, Christen S, Peterhans E \& Stocker R (1992). Oxidative stress in lungs of mice infected with influenza A virus. Free Radical Research Communications, 16: 99-110.
4. Oda T, Akaike T, Hamamoto T, Suzuki F, Hirano T \& Maeda H (1989). Oxygen radicals in influenza-induced pathogenesis and treatment with pyran polymer-conjugated SOD. Science, 244: 974-976.

5. Halliwell B \& Gutteridge JMC (1989). Free Radicals in Biology and Medicine. 2nd edn. Clarendon Press, Oxford.

6. Niles WD, Peeples ME \& Cohen FS (1990). Kinetics of virus-induced hemolysis measured for single erythrocyte. Virology, 174: 593-598.

7. Puppo A \& Halliwell B (1988). Formation of hydroxyl radicals from hydrogen peroxide in the presence of iron. Is haemoglobin a biological Fenton reagent? Biochemical Journal, 249: 185-190.
8. Halliwell B (1985). Use of desferrioxamine as a "probe" for iron-dependent formation of hydroxyl radicals. Biochemical Pharmacology, 32: 229-233.

9. Sharonov BP, Dolganova AV \& Kiselev OI (1991). The effective use of superoxide dismutase from human erythrocytes in the late stages of experimental influenza infection. Voprosy Virusologii, 36: 477480.

10. Petrone WF, English DK, Wong K \& McCord JM (1980). Free radicals and inflammation: superoxide-dependent activation of a neutrophil chemotactic factor in plasma. Proceedings of the National Academy of Sciences, USA, 77: 1159-1163. 
11. Hallaway PE, Eaton JW, Panter SS \& Hedlund BE (1989). Modulation of desferrioxamine toxicity and clearance by covalent attachment to biocompatible polymers. Proceedings of the National Academy of Sciences, USA, 86: 10108-10112.

12. Blake DR, Hall ND, Bacon PA, Dieppe PA Halliwell B \& Gutteridge JMC (1983). Effect of a specific iron chelating agent on animal models of inflammation. Annals of the Rheumatic Diseases, 42: 89-93.

13. Borg DA \& Schaich KM (1986). Prooxidant action of desferrioxamine: Fenton-like production of hydroxyl radicals by reduced ferrioxamine. Free Radical Biology and Medicine, 2: 237-243.
14. Miller DM, Spear NH \& Aust SD (1992) Effect of desferrioxamine on iron-catalysed lipid peroxidation. Archives of Biochemistry and Biophysics, 295: 240-246.

15. De Matteis F, Dawson SJ \& Gibbs AH (1993). Two pathways of iron-catalysed oxidation of bilirubin: effect of desferrioxamine and trolox, and comparison with microsomal oxidation. Free Radical Biology and Medicine, 15: 301-309.

16. Davies MJ, Donkor R, Dunster CA, Gee CA, Jonas S \& Willson RL (1987). Desferrioxamine (desferal) and superoxide free radicals. Formation of an enzyme-damaging nitroxide. Biochemical Journal, 246 725-729.
17. Yegorov DYu, Kozlov AV, Azizova OA \& Vladimirov YuA (1993). Simultaneous determination of $\mathrm{Fe}$ (III) and $\mathrm{Fe}$ (II) in water solutions and tissue homogenates using desferal and 1,10-phenanthroline. Free Radical Biology and Medicine, 15: 565574 